\title{
Effects of comprehensive pulmonary rehabilitation therapy on pulmonary functions and blood gas indexes of patients with severe pneumonia
}

\author{
WEI LIU ${ }^{1 *}$, XURI MU²* ${ }^{*}$ XIN WANG ${ }^{3}$, PEIPEI ZHANG ${ }^{4}, \mathrm{LI} \mathrm{ZHAO}^{5}$ and QIUJU LI $^{6}$ \\ ${ }^{1}$ Emergent Intensive Care Unit, Jining No. 1 People's Hospital, Jining, Shandong 272011; ${ }^{2}$ Department of \\ Cardiothoracic Surgery, Yantaishan Hospital, Yantai, Shandong 264000; Departments of ${ }^{3}$ Magnetic Resonance and \\ ${ }^{4}$ Cardiology, People's Hospital of Zhangqiu District, Zhangqiu, Shandong 250200; \\ ${ }^{5}$ Department of Respiratory Medicine, People's Hospital of Rizhao, Rizhao, Shandong 276800; ${ }^{6}$ Department of \\ Adult Rehabilitation, Jining No. 1 People's Hospital, Jining, Shandong 272011, P.R. China
}

Received December 19, 2017; Accepted June 12, 2018

DOI: $10.3892 /$ etm.2018.6396

\begin{abstract}
In this study we try to observe the effects of comprehensive pulmonary rehabilitation therapy on pulmonary functions and blood gas indexes of patients with severe pneumonia during mechanical ventilation. A total of 120 patients with severe pneumonia were selected and divided into the experimental group $(n=60)$ and the control group $(n=60)$ through a random number table. Conventional therapy for severe pneumonia was applied to patients in both groups, and the experimental group was additionally treated with comprehensive pulmonary rehabilitation therapy, including warming-up exercise before training, respiratory function exercise, respiratory muscle training, health education, psychological support and nutritional intervention. The pulmonary function indexes, blood gas indexes, Borg index scores and 6-min walk distance (6MWD) of the two groups of patients were evaluated before treatment and at 6 months after treatment, respectively. In the control group, there were statistically significant differences only in forced expiratory volume in $1 \mathrm{sec}$ (FEV1), ratio of FEV1 to forced vital capacity (FEV1/FVC), partial pressure of $\mathrm{O}_{2}\left(\mathrm{PaO}_{2}\right)$, arterial partial pressure of carbon dioxide $\left(\mathrm{PaCO}_{2}\right)$, Borg index and 6MWD after treatment compared with those before treatment $(\mathrm{P}<0.05)$; as for intragroup comparisons, there were no significant improvements in other indexes compared with those before treatment, and the differences were not statistically significant $(\mathrm{P}>0.05)$. In
\end{abstract}

Correspondence to: Dr Qiuju Li, Department of Adult Rehabilitation, Jining No. 1 People's Hospital, No. 6 Jiankang Road, Jining, Shandong 272011, P.R. China

E-mail: qs59pf@163.com

${ }^{*}$ Contributed equally

Key words: pulmonary rehabilitation therapy, severe pneumonia, mechanical ventilation, pulmonary functions, blood gas indexes the experimental group, all the indexes after treatment were statistically different from those before treatment and those after treatment in the control group $(\mathrm{P}<0.05)$; with regard to comparisons of the indexes between the control group and the experimental group, the differences were significant $(\mathrm{P}<0.05)$. Comprehensive pulmonary rehabilitation therapy is conducive to improving the pulmonary functions and blood gas indexes of patients with severe pneumonia during mechanical ventilation.

\section{Introduction}

Severe pneumonia is a common kind of community-acquired infection in the respiratory department, with serious conditions, rapid development and long course; it can easily induce respiratory failure and affect many other organs, seriously influencing the patient's quality of life $(1,2)$. The death rate of patients with severe pneumonia is relatively high, and it is the highest among the infectious diseases, being at approximately 20-50\%; the respiratory functions of patients with severe pneumonia have been greatly affected due to high-permeability edema, hyperemia and inflammatory exudation of lung tissues, as well as increased respiratory secretions $(3,4)$. Mechanical ventilation is a very important auxiliary means to treat patients with severe pneumonia; it can effectively ameliorate the pulmonary ventilation and gas exchange functions of the patients, but it can seriously affect the sputum expectoration of the patients and cause dyspnea because its inevitable side-effects may also further lead to reduced functions of the respiratory tract in the patients $(5,6)$. Therefore, effective and safe therapeutic modes are extremely important for symptom improvement and prognosis of the patients during mechanical ventilation.

The principles of pulmonary rehabilitation therapy have not been completely elaborated yet; the main functions of the therapy are to enhance the patients' exercise capacity, improve the respiratory function reserve and ameliorate the patients' cardiopulmonary functions. Its advantages are that it can alleviate the patients' symptoms, relieve and even reverse the progression of disease and lower the cost of treatment in an effective manner (7). 
Table I. Comparisons of basic data between the two groups.

\begin{tabular}{lccr}
\hline & Control group $(\mathrm{n}=60)$ & Experimental group $(\mathrm{n}=60)$ & P-value \\
\hline $\begin{array}{l}\text { Age }(\text { years }) \\
\text { Sex } \mathrm{n}(\%)\end{array}$ & $52.3 \pm 9.6$ & $56.7 \pm 13.6$ & 0.871 \\
$\quad$ Male/female & $32(53.33) / 28(46.67)$ & $41(68.33) / 19(31.67)$ & 0.329 \\
Body temperature & $37.91 \pm 0.42$ & $37.81 \pm 0.53$ & 0.891 \\
Weight $(\mathrm{kg}), \mathrm{n}(\%)$ & & & 0.759 \\
$<50$ & $21(35.00)$ & $25(41.67)$ & 0.672 \\
$\geq 50$ & $39(65.00)$ & $35(58.33)$ & \\
Nation, $\mathrm{n}(\%)$ & $53(88.33)$ & $56(93.33)$ & 0.456 \\
Han & $7(11.67)$ & $4(6.67)$ & \\
Minority & & $46(76.67)$ & $14(23.33)$ \\
Place of residence, $\mathrm{n}(\%)$ & $40(66.67)$ & $30.82 \pm 2.31$ & 0.853 \\
City & $20(33.33)$ & $12.59 \pm 1.99$ & 0.882 \\
Countryside & $31.64 \pm 2.56$ & $13.21 \pm 1.71$ & \\
C-reactive protein & & & \\
White blood cell count & & & \\
\hline
\end{tabular}

In the present study, the effects of comprehensive pulmonary rehabilitation therapy on the pulmonary functions and blood gas indexes of 60 patients with severe pneumonia during mechanical ventilation were observed, so as to investigate the role of conventional therapy for severe pneumonia assisted by comprehensive pulmonary rehabilitation therapy. The results are shown below.

\section{Materials and methods}

Clinical data. A total of 120 patients diagnosed with severe pneumonia in Jining No. 1 People's Hospital (Jining, China) from May 2013 to May 2015 were selected; the diagnostic criteria were based on the Guidelines for Diagnosis and Treatment of Community-Acquired Pneumonia in Chinese Adults (2016 Version). All the patients were divided into the experimental group $(n=60)$ and the control group $(n=60)$ through a random number table. Conventional therapy for severe pneumonia was applied to patients in both groups, and the experimental group was additionally treated with comprehensive pulmonary rehabilitation therapy. Patients with the following conditions were excluded: unstable coronary heart disease; intermittent myocardial infarction; severe pulmonary arterial hypertension; serious osteoarthrosis or fracture; mental disorders or learning disability. This research was approved by the Ethics Committee of the Jining No. 1 People's Hospital, and informed consent was signed by the patients or their families.

Therapeutic methods. For the conventional therapy, conventional anti-infection therapy was adopted. In regards to the pulmonary rehabilitation therapy, warming-up exercise before training, respiratory function exercise, respiratory muscle training, health education, psychological support and nutritional intervention were performed for the patients by the physicians and the nurses.
Observation indexes. The pulmonary function indexes, blood gas indexes, Borg index and 6-min walk distance (6MWD) of the two groups of patients with severe pneumonia were observed before treatment and at 6 months after treatment, and intra-group and inter-group comparisons were conducted.

Statistical analysis. Statistical Product and Service Solutions (SPSS) 19.0 software (IBM Corp., Armonk, NY, USA) was used for the statistical analysis. Comparison between groups was done using One-way ANOVA test followed by post hoc test (Least Significant Difference). The measurement data were presented as mean $\pm \mathrm{SD}$, and non-parametric Kolmogorov-Smirnov (K-S) test was performed for the comparisons between the two groups. $\mathrm{P}<0.05$ indicated a statistically significant difference.

\section{Results}

Basic data. Among the 120 patients with severe pneumonia, there were 73 males and 47 females, with an average age of $54.5 \pm 11.6$ years old. The patients were randomly divided into the control group $(n=60)$ and the experimental group $(\mathrm{n}=60)$; in the control group, there were 32 male patients and 28 female patients, with an average age of $52.3 \pm 9.6$ years old; the experimental group consisted of 41 male patients and 19 female patients, with an average age of $56.7 \pm 13.6$ years old. There were no remarkable differences in the basic data, such as sex, weight and age, between the control group and the experimental group $(\mathrm{P}>0.05)$ (Table I).

Changes in pulmonary function indexes before treatment and at 6 months after treatment. Before treatment, there were no differences in the pulmonary function parameters between the two groups ( $\mathrm{P}>0.05)$; at 6 months after treatment, as for the comparisons within the control group, there were differences only in vital capacity (VC) $(1.63 \pm 0.21$ vs. $2.21 \pm 0.32$, 
Table II. Changes in pulmonary function parameters of the two groups of patients before treatment and at 6 months after treatment.

\begin{tabular}{cccc}
\hline & $\begin{array}{c}\text { Control } \\
\text { group }(\mathrm{n}=60)\end{array}$ & $\begin{array}{c}\text { Experimental } \\
\text { group }(\mathrm{n}=60)\end{array}$ & P-value \\
\hline VC (L) & & & \\
Before treatment & $1.63 \pm 0.21$ & $1.71 \pm 0.31$ & 0.853 \\
After treatment & $2.21 \pm 0.32$ & $2.58 \pm 0.72$ & 0.042 \\
FEV1 (L) & & & \\
Before treatment & $1.14 \pm 0.18$ & $1.22 \pm 0.24$ & 0.862 \\
After treatment & $1.57 \pm 0.19$ & $2.11 \pm 0.32$ & 0.035 \\
FEV1/FVC (\%) & & & \\
Before treatment & $41.22 \pm 5.38$ & $39.59 \pm 5.01$ & 0.725 \\
After treatment & $71.15 \pm 6.44$ & $82.09 \pm 7.13$ & 0.036 \\
MMEF (L/sec) & & & \\
Before treatment & $1.15 \pm 0.23$ & $1.14 \pm 0.19$ & 0.987 \\
After treatment & $1.32 \pm 0.26$ & $1.81 \pm 0.31$ & 0.042 \\
PEF (L/sec) & & & \\
Before treatment & $4.11 \pm 0.52$ & $4.04 \pm 0.44$ & 0.902 \\
After treatment & $4.54 \pm 0.42$ & $5.25 \pm 0.56$ & 0.039 \\
\hline
\end{tabular}

Table III. Changes in blood gas indexes of the two groups of patients before treatment and at 6 months after treatment.

\begin{tabular}{|c|c|c|c|}
\hline & $\begin{array}{c}\text { Control } \\
\text { group }(n=60)\end{array}$ & $\begin{array}{l}\text { Experimental } \\
\text { group }(n=60)\end{array}$ & P-value \\
\hline \multicolumn{4}{|l|}{$\mathrm{PaO}_{2}(\mathrm{mmHg})$} \\
\hline Before treatment & $57.66 \pm 6.03$ & $58.26 \pm 5.58$ & 0.856 \\
\hline After treatment & $78.03 \pm 6.78$ & $86.21 \pm 6.33$ & 0.026 \\
\hline \multicolumn{4}{|l|}{$\mathrm{PaCO}_{2}(\mathrm{mmHg})$} \\
\hline Before treatment & $67.22 \pm 7.48$ & $65.43 \pm 7.89$ & 0.874 \\
\hline After treatment & $51.57 \pm 7.96$ & $45.85 \pm 7.01$ & 0.031 \\
\hline \multicolumn{4}{|l|}{$\mathrm{SaO}_{2}($ time/min $)$} \\
\hline Before treatment & $86.21 \pm 4.14$ & $88.65 \pm 4.22$ & 0.816 \\
\hline After treatment & $92.33 \pm 3.59$ & $95.26 \pm 5.02$ & 0.042 \\
\hline
\end{tabular}

$\mathrm{P}=0.021)$, forced expiratory volume in $1 \mathrm{sec}(\mathrm{FEV} 1)(1.14 \pm 0.18$ vs. $1.57 \pm 0.19, \mathrm{P}=0.036)$ and ratio of $\mathrm{FEV} 1$ to forced vital capacity (FEV1/FVC) $(41.22 \pm 5.38$ vs. $71.15 \pm 6.44, \mathrm{P}=0.025)$, and there were no differences in maximum mid-expiratory flow (MMEF) $(1.15 \pm 0.23$ vs. $1.32 \pm 0.26, \mathrm{P}=0.095)$ and peak expiratory flow (PEF) $(4.11 \pm 0.52$ vs. $4.54 \pm 0.42, \mathrm{P}=0.574)$. For the comparisons within the experimental group, the VC $(1.71 \pm 0.31$ vs. $2.58 \pm 0.72, \mathrm{P}=0.025)$, FEV1 $(1.22 \pm 0.24$ vs. $2.11 \pm 0.32$, $\mathrm{P}=0.036), \mathrm{FEV} 1 / \mathrm{FVC}(39.59 \pm 5.01$ vs. 82.09 $\pm 7.13, \mathrm{P}=0.014)$, MMEF $(1.14 \pm 0.19$ vs. $1.81 \pm 0.31, \mathrm{P}=0.046)$ and $\mathrm{PEF}(4.04 \pm 0.44$ vs. $5.25 \pm 0.56, \mathrm{P}=0.039)$ were different. In terms of inter-group comparison, there were differences in VC $(2.21 \pm 0.32 \mathrm{vs}$. $2.58 \pm 0.72, \mathrm{P}=0.042)$, FEV1 (1.57 \pm 0.19 vs. $2.11 \pm 0.32, \mathrm{P}=0.035)$, FEV1/FVC (71.15 \pm 6.44 vs. 82.09 $\pm 7.13, \mathrm{P}=0.036), \mathrm{MMEF}$

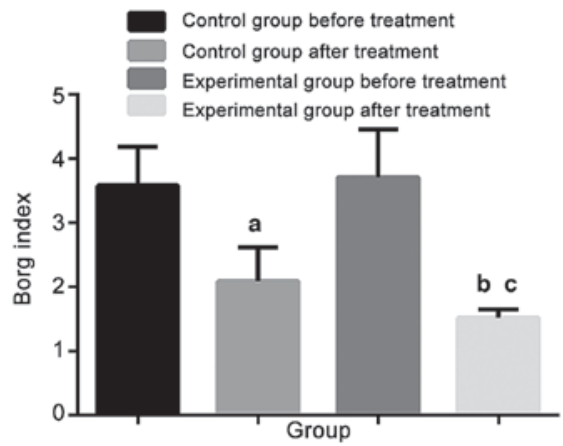

Figure 1. Changes in Borg index before treatment and at 6 months after treatment. There is no difference in the Borg index between the two groups of patients before treatment $(\mathrm{P}>0.05)$; at 6 months after treatment, the Borg index (3.58 \pm 0.61 vs. $2.09 \pm 0.53, \mathrm{P}=0.021)$ within the control group is improved. For intra-group comparison in the experimental group, the Borg index $(3.71 \pm 0.75$ vs. $1.52 \pm 0.13, \mathrm{P}=0.012)$ is improved. The Borg index $(2.09 \pm 0.53$ vs. $1.52 \pm 0.13, \mathrm{P}=0.032)$ in the experimental group is improved more obviously compared with that in the control group. Compared with control group before treatment, ${ }^{\text {a }} \mathrm{P}<0.05$; Compared with experimental group before treatment, ${ }^{b} \mathrm{P}<0.05$; Compared with control group after treatment, ${ }^{\mathrm{c}} \mathrm{P}<0.05$.

$(1.32 \pm 0.26$ vs. $1.81 \pm 0.31, \mathrm{P}=0.042)$ and $\mathrm{PEF}(4.54 \pm 0.42$ vs $5.25 \pm 0.56, \mathrm{P}=0.039)$ between the control group and the experimental group. Conventional therapy assisted by comprehensive pulmonary rehabilitation therapy has better improvement effects on the pulmonary functions of patients with severe pneumonia during mechanical ventilation (Table II).

Changes in blood gas indexes before treatment and at 6 months after treatment. There were no differences in the blood gas indexes between the two groups before treatment $(\mathrm{P}>0.05)$; as for the comparisons within the control group at 6 months after treatment, there were differences in partial pressure of $\mathrm{O}_{2}$ $\left(\mathrm{PaO}_{2}\right)(57.66 \pm 6.03$ vs. $78.03 \pm 6.78, \mathrm{P}=0.022)$ and arterial partial pressure of carbon dioxide $\left(\mathrm{PaCO}_{2}\right)(67.22 \pm 7.48$ vs. $51.57 \pm 7.96$, $\mathrm{P}=0.035)$, and there was no difference in arterial $\mathrm{O}_{2}$ saturation $\left(\mathrm{SaO}_{2}\right)(86.21 \pm 4.14$ vs. $92.33 \pm 3.59, \mathrm{P}=0.135)$. For the comparisons within the experimental group, the $\mathrm{PaO}_{2}(58.26 \pm 5.58$ vs. $86.21 \pm 6.33, \mathrm{P}=0.022), \mathrm{PaCO}_{2}(65.43 \pm 7.89$ vs. $45.85 \pm 7.01$, $\mathrm{P}=0.029)$ and $\mathrm{SaO}_{2}(88.65 \pm 4.22$ vs. $95.26 \pm 5.02, \mathrm{P}=0.035)$ had differences. With regard to inter-group comparisons, there were differences in $\mathrm{PaO}_{2}(78.03 \pm 6.78$ vs. 86.21 $\pm 6.33, \mathrm{P}=0.026)$ and $\mathrm{PaCO}_{2}(51.57 \pm 7.96$ vs. $45.85 \pm 7.01, \mathrm{P}=0.031)$ between the control group and the experimental group. Conventional therapy assisted by comprehensive pulmonary rehabilitation therapy has more significant improvement effects on $\mathrm{PaO}_{2}$ and $\mathrm{PaCO}_{2}$ of patients with severe pneumonia during mechanical ventilation (Table III).

Changes in Borg index before treatment and at 6 months after treatment. There was no difference in the Borg index between the two groups of patients before treatment $(\mathrm{P}>0.05)$; at 6 months after treatment, the Borg index $(3.58 \pm 0.61 \mathrm{vs}$. $2.09 \pm 0.53, \mathrm{P}=0.021)$ within control group was improved. For intra-group comparison in experimental group, the Borg index (3.71 \pm 0.75 vs. $1.52 \pm 0.13, \mathrm{P}=0.012)$ was improved. The Borg index $(2.09 \pm 0.53$ vs. $1.52 \pm 0.13, \mathrm{P}=0.032)$ in experimental group was improved more obviously compared with that in control group (Fig. 1). 


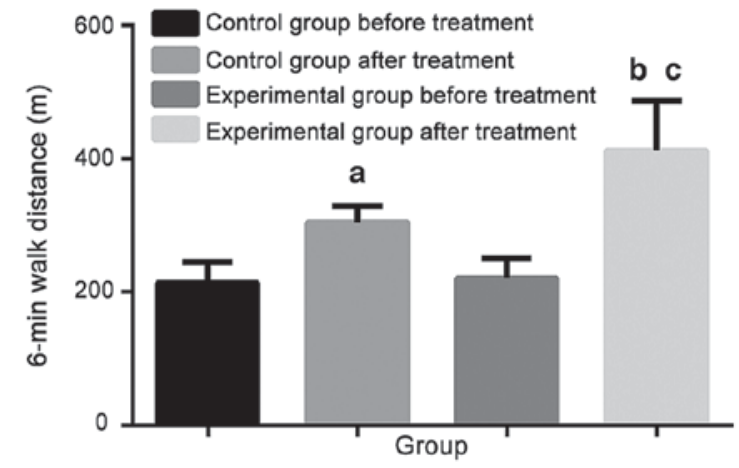

Figure 2. Comparison of 6MWD results before treatment and at 6 months after treatment. Before treatment, there is no difference in the $6 \mathrm{MWD}$ between the two groups of patients $(\mathrm{P}>0.05)$; at 6 months after treatment, in the control group, the 6MWD $(214.32 \pm 31.02$ vs. $304.71 \pm 24.33, \mathrm{P}=0.026)$ is improved, and in the experimental group, the 6MWD $(221.11 \pm 29.59$ vs. $412.45 \pm 74.77, \mathrm{P}=0.012)$ is also improved. As for comparison of the 6MWD (304.71 \pm 24.33 vs. $412.45 \pm 74.77, \mathrm{P}=0.035)$ between the control group and the experimental group, the improvement in experimental group is more remarkable. Compared with control group before treatment, ${ }^{a} \mathrm{P}<0.05$; Compared with experimental group before treatment, ${ }^{b} \mathrm{P}<0.05$; Compared with control group after treatment, ${ }^{\mathrm{C}} \mathrm{P}<0.05$.

Changes in 6MWD results before treatment and at 6 months after treatment $(m)$. Before treatment, there was no difference in the 6MWD between the two groups of patients $(\mathrm{P}>0.05)$; at 6 months after treatment, in the control group, the 6MWD $(214.32 \pm 31.02$ vs. $304.71 \pm 24.33, \mathrm{P}=0.026)$ was improved, and in the experimental group, the 6MWD $(221.11 \pm 29.59$ vs. $412.45 \pm 74.77, \mathrm{P}=0.012$ ) was also improved. As for the comparison of the 6MWD $(304.71 \pm 24.33$ vs. $412.45 \pm 74.77$, $\mathrm{P}=0.035$ ) between the control group and the experimental group, the improvement in the experimental group was more remarkable (Fig. 2).

\section{Discussion}

Bacterial pneumonia is a major complication of severe pneumonia, and it is a main reason for respiratory failure of the patients with severe pneumonia; in addition, it can induce respiratory distress syndrome of the patients and lead to poor prognosis and even death of the patients with severe pneumonia $(4,8)$. Mechanical ventilation is an indispensable support means for treatment of patients with severe pneumonia, but it is prone to cause lung injury and bacterial infections, in the patients, which has extremely adverse effects on the weaning and prognosis of the patients $(9,10)$. Therefore, the pulmonary rehabilitation therapy was applied in this study. The pulmonary rehabilitation therapy is an important part of management of patients with respiratory diseases, and it plays an active role in improving the patients' pulmonary functions and immunity $(11,12)$. It was expected that the introduction of pulmonary rehabilitation therapy could relieve and even reverse the lung injury and other complications of the patients with severe pneumonia during mechanical ventilation.

In the present study, the results of conventional therapy and pulmonary rehabilitation therapy applied to 120 patients with severe pneumonia during mechanical ventilation were summarized. The duration of this research was 6 months, and patients with contraindications for pulmonary rehabilitation therapy were excluded; meanwhile, the approval was obtained from the ethics committee of the hospital, and the informed consent was signed by the patients or their families.

It was found through the results of this study that the pulmonary function indexes of the patients with severe pneumonia in experimental group who received conventional therapy assisted by pulmonary rehabilitation therapy were notably better than those of the patients in control group who received simple conventional therapy. It proves that pulmonary rehabilitation therapy is of positive significance to ameliorating the pulmonary functions of the patients with severe pneumonia during mechanical ventilation. Pulmonary rehabilitation therapy is a pattern of combined treatment for patients' exercise capacity, remission of disease, recovery of pulmonary function and psychology, which integrates prevention and treatment (13). The results of this study also revealed that pulmonary rehabilitation therapy effectively improved the MMEF and PEF and increased the VC and FEV1 of the patients, thus ameliorating their pulmonary ventilation and gas exchange functions. Lacasse et al (14) also indicated in their study results that pulmonary rehabilitation therapy can ameliorate dyspnea and improve the motor function of the patients in an effective manner. In this study, the 6MWD of the patients was measured, and the results showed that the 6MWD of the patients receiving pulmonary rehabilitation therapy was improved effectively, and the Borg index was also ameliorated significantly. The improvement of exercise capacity is crucial to patients' further recovery from the disease, not only to the enhancement of immunity, but also to the improvement of information for disease recovery of the patients (15). However, the results of this study were partially different from those of McCarthy et al whose results did not discover that pulmonary rehabilitation therapy can improve FEV1, which may be caused by different research objects; in the study of McCarthy et al, patients with chronic obstructive pulmonary disease were enrolled as the major research objects. There are few studies on the treatment effect of pulmonary rehabilitation therapy in severe pneumonia; therefore, the results of this study are only for reference, and pulmonary rehabilitation therapy is mainly used to treat chronic pulmonary diseases (16). Güell et al (17) conducted a 3-year pulmonary rehabilitation therapy for patients with severe chronic obstructive pulmonary disease; it was found that the pulmonary rehabilitation therapy has treatment effects only in the first 2 years, and that its effects are not significant any more in 2 years later. It provides a very important guidance for this study; since the follow-up was conducted for only 6 months in this research, whether the pulmonary rehabilitation therapy would be effective in a longer duration of follow-up still remains unknown, which needs to be investigated in the future. In addition, the blood gas indexes of the patients with severe pneumonia were evaluated in this study, and the results proved that the pulmonary rehabilitation therapy has remarkable improvement effects on the patients' $\mathrm{PaO}_{2}, \mathrm{PaCO}_{2}$ and $\mathrm{SaO}_{2}$. It was also reported in the study of Huppmann et al (18) on the pulmonary rehabilitation therapy for patients with interstitial pneumonia that the therapy can ameliorate the blood gas indexes in an effective manner. It is consistent with the results of this research, although the research objects are different. The pulmonary rehabilitation therapy can effectively improve the blood gas indexes of patients with chronic obstructive pulmonary disease in the stable phase (19) and even 
non-small cell lung cancers (20); all these have proven that the pulmonary rehabilitation therapy has improvement effects on the recovery of pulmonary functions and the exchange capacity between oxygen and carbon dioxide in the body of the patients.

In conclusion, comprehensive pulmonary rehabilitation therapy is conducive to improving the pulmonary functions and blood gas indexes of patients with severe pneumonia during mechanical ventilation, and it is beneficial to the exchange capacity between oxygen and carbon dioxide in the body of the patients.

\section{Acknowledgements}

Not applicable.

\section{Funding}

No funding was received.

\section{Availability of data and materials}

All data generated or analyzed during this study are included in this published article.

\section{Authors' contributions}

WL and XM wrote the manuscript. WL, XW, PZ and XM were responsible for collecting patient data. XW, QL and $\mathrm{LZ}$ analyzed the patient data. All authors read and approved the final study.

\section{Ethics approval and consent to participate}

This research was approved by the Ethics Committee of the Jining No. 1 People's Hospital (Jining, China), and informed consent was signed by the patients or their families.

\section{Patient consent for publication}

Not applicable.

\section{Competing interests}

The authors declare that they have no competing interests.

\section{References}

1. Ceccato A, Cilloniz C, Ranzani OT, Menendez R, Agusti C, Gabarrus A, Ferrer M, Sibila O, Niederman MS and Torres A: Treatment with macrolides and glucocorticosteroids in severe community-acquired pneumonia: A post-hoc exploratory analysis of a randomized controlled trial. PLoS One 12: e0178022, 2017.

2. Feikin DR, Fu W, Park DE, Shi Q, Higdon MM, Baggett HC, Brooks WA, Deloria Knoll M, Hammitt LL, Howie SRC, et al; PERCH Study Group: Is higher viral load in the upper respiratory tract associated with severe pneumonia? Findings From the PERCH Study. Clin Infect Dis 64 (suppl_3): S337-S346, 2017.

3. Agweyu A, Gathara D, Oliwa J, Muinga N, Edwards T, Allen E, Maleche-Obimbo E, English M, Aweyo F, Awuonda B, et al Severe Pneumonia Study Group: Oral amoxicillin versus benzyl penicillin for severe pneumonia among kenyan children: A pragmatic randomized controlled noninferiority trial. Clin Infect Dis 60: 1216-1224, 2015.
4. Tagami T, Matsui H, Horiguchi H, Fushimi $\mathrm{K}$ and Yasunaga $\mathrm{H}$ : Recombinant human soluble thrombomodulin and mortality in severe pneumonia patients with sepsis-associated disseminated intravascular coagulation: An observational nationwide study. J Thromb Haemost 13: 31-40, 2015.

5. Patel BK and Hall JB: Perioperative physiotherapy. Curr Opin Anaesthesiol 26: 152-156, 2013.

6. McCauley P and Datta D: Management of COPD patients in the intensive care unit. Crit Care Nurs Clin North Am 24: 419-430, 2012.

7. Spruit MA, Singh SJ, Garvey C, ZuWallack R, Nici L, Rochester C, Hill K, Holland AE, Lareau SC, Man WD, et al; ATS/ERS Task Force on Pulmonary Rehabilitation: An official American Thoracic Society/European Respiratory Society statement: Key concepts and advances in pulmonary rehabilitation. Am J Respir Crit Care Med 188: e13-e64, 2013.

8. Ngari MM, Fegan G, Mwangome MK, Ngama MJ, Mturi N, Scott JAG, Bauni E, Nokes DJ and Berkley JA: Mortality after inpatient treatment for severe pneumonia in children: A cohort study. Paediatr Perinat Epidemiol 31: 233-242, 2017.

9. Esteban A, Frutos-Vivar F, Muriel A, Ferguson ND, Peñuelas O, Abraira V, Raymondos K, Rios F, Nin N, Apezteguía C, et al: Evolution of mortality over time in patients receiving mechanical ventilation. Am J Respir Crit Care Med 188: 220-230, 2013.

10. Young D, Harrison DA, Cuthbertson BH, Rowan $\mathrm{K}$ and Collaborators F; TracMan Collaborators: Effect of early vs late tracheostomy placement on survival in patients receiving mechanical ventilation: The TracMan randomized trial. JAMA 309: 2121-2129, 2013.

11. Spruit MA, Pitta F, Garvey C, ZuWallack RL, Roberts CM, Collins EG, Goldstein R, McNamara R, Surpas P, Atsuyoshi K, et al; ERS Rehabilitation and Chronic Care, and Physiotherapists Scientific Groups; American Association of Cardiovascular and Pulmonary Rehabilitation; ATS Pulmonary Rehabilitation Assembly and the ERS COPD Audit team: Differences in content and organisational aspects of pulmonary rehabilitation programmes. Eur Respir J 43: 1326-1337, 2014.

12. Ryerson CJ, Cayou C, Topp F, Hilling L, Camp PG, Wilcox PG, Khalil N, Collard HR and Garvey C: Pulmonary rehabilitation improves long-term outcomes in interstitial lung disease: A prospective cohort study. Respir Med 108: 203-210, 2014.

13. Corhay JL, Dang DN, Van Cauwenberge H and Louis R: Pulmonary rehabilitation and COPD: Providing patients a good environment for optimizing therapy. Int J Chron Obstruct Pulmon Dis 9: 27-39, 2014.

14. Lacasse Y, Brosseau L, Milne S, Martin S, Wong E, Guyatt GH and Goldstein RS: Pulmonary rehabilitation for chronic obstructive pulmonary disease. Cochrane Database Syst Rev 88: CD003793, 2002.

15. Chang G, Meadows ME, Orav EJ and Antin JH: Mental status changes after hematopoietic stem cell transplantation. Cancer 115: 4625-4635, 2009.

16. McCarthy C, Brennan JR, Brown L, Donaghy D, Jones P, Whelan R, McCormack N, Callanan I, Ryan J and McDonnell TJ: Use of a care bundle in the emergency department foracute exacerbations of chronic obstructive pulmonary disease:a feasibility study. Int J Chron Obstruct Pulmon Dis 8: 605-611, 2013.

17. Güell MR, Cejudo P, Ortega F, Puy MC, Rodríguez-Trigo G, Pijoan JI, Martinez-Indart L, Gorostiza A, Bdeir K, Celli B, et al: Benefits of long-term pulmonary rehabilitation maintenance program in patients with severe chronic obstructive pulmonary sisease. Three-Year Follow-up. Am J Respir Crit Care Med 195: 622-629, 2017.

18. Huppmann P, Sczepanski B, Boensch M, Winterkamp S, Schönheit-Kenn U, Neurohr C, Behr J and Kenn K: Effects of inpatient pulmonary rehabilitation in patients with interstitial lung disease. Eur Respir J 42: 444-453, 2013.

19. Struik FM, Lacasse Y, Goldstein RS, Kerstjens HA and Wijkstra PJ: Nocturnal noninvasive positive pressure ventilation in stable COPD: A systematic review and individual patient data meta-analysis. Respir Med 108: 329-337, 2014.

20. Tokarski S, Tokarska K, Schwarz E, Obrebska A, Mejer A and Kowalski J: Blood gas analysis, blood saturation and chosen parameters of spirometric examination in NSCLC patients undergoing chemotherapy and pulmonary rehabilitation. Pol Merkur Lekarski 36: 249-253, 2014. 